\title{
El acto de interpretación como proceso de identificación de atributos para la caracterización en personajes animados
}

\section{Resumen}

El presente documento busca darle una mirada a las relaciones entre la animación y la actuación como saberes involucrados íntimamente con el movimiento y el cuerpo, así como identificar los aportes que entre ambos surgen y la evolución que se dio para llegar a dicha simbiosis. Desde esta perspectiva se detecta una interacción clara de los dispositivos tecnológicos de captura, a manera de integración entre ambas disciplinas mediante el proceso de registro corporal previo y su análisis sintetizado en formas y trazos, siendo a su vez el esquema más reconocido a través del cual la animación ha tenido su desarrollo como sistema de representación audiovisual. No se busca desarrollar una metodología nueva, sino evidenciar los usos y campos de interacción que ya existen desde hace décadas en producciones internacionales, pero que aún no son suficientemente utilizados en el panorama nacional, creando una brecha en la apropiación de una las prácticas más recurrentes para los animadores profesionales como lo es el Acting. Desde la observación y la constatación de las diferencias y similitudes entre ambas disciplinas, se construyeron pilotos de trabajo que buscaban acercar la labor del actor a la del animador, no como una subordinación de uno a hacia otro en cualquier sentido, sino como una cooperación interdisciplinar que potencia el lenguaje animado. Para corroborar las hipótesis planteadas frente a estos vínculos entre la interpretación actoral y el fenómeno animado, se desarrollaron diferentes prácticas con animadores y actores girando alrededor de guiones y narrativas para animación, los cuales permitieron la construcción de escenarios de cooperación en pos de una mejor caracterización de los personajes en su interior. Finalmente se pudo observar una evolución en las competencias de los participantes, tanto en su saber propio como en el sentido que le dieron a su homólogo desde el otro frente del movimiento.
Jesús Alejandro Guzmán Ramírez

Doctor en Diseño y Creación. Universidad Jorge Tadeo Lozano Bogotá - Colombia Correo electrónico: jesusa.guzmanr@utadeo.edu.co aguzman789@hotmail.com ๑ orcid.org//0000-0001-8249-2114

\section{Google Scholar}

Jose Angel Cabuya Velandia Diseñador Gráfico Universidad Jorge Tadeo Lozano Bogotá - Colombia Correo electrónico: josea.cabuyav@utadeo.edu.co ๑ orcid.org/0000-0002-7008-9923 Google Scholar

Recibido: julio 26 de 2018 Aprobado: mayo 22 de 2020

Palabras clave:

Acting, animación, forma, cuerpo, representación. 


\section{The act of interpretation as a process to identify attributes for characterization in animated characters}

\begin{abstract}
This document seeks to take a look at the relationships between animation and performance as knowledge intimately involved with movement and the body, as well as to identify the contributions that arise between both of them and the evolution that took place to reach this symbiosis. From this perspective, a clear interaction of the technological capture devices is detected as an integration between both disciplines through the process of prior body registration and its analysis synthesized in shapes and strokes, being in turn the most recognized scheme through which the animation has had its development as an audiovisual representation system. The aim is not to develop a new methodology, but rather to show the uses and fields of interaction that have already existed for decades in international productions, but that are not yet sufficiently used in the national scene, creating a gap in the appropriation of one of the most recurrent practices for professional entertainers such as Acting. From the observation and verification of the differences and similarities between both disciplines, work pilots were built that sought to bring the work of the actor closer to that of the animator, not as a subordination of one to another in any sense, but as an interdisciplinary cooperation that enhances animated language. To corroborate the hypotheses raised regarding these links between acting performance and the animated phenomenon, different practices were developed with animators and actors revolving around scripts and narratives for animation, which allowed the construction of cooperation scenarios in pursuit of a better characterization of the characters inside. Finally, it was possible to observe an evolution in the competences of the participants, both in their own knowledge and in the sense they gave to their counterpart from the other front of the movement.
\end{abstract}

Key words: acting, animation, shape, body, representation. 


\section{Introducción}

Como punto de partida, en el presente documento se concibe la animación como un proceso que se enmarca en la dimensión del diseño de movimiento, el cual busca en sí mismo el medio para que la representación de una idea de movimiento —o ideokinesis (Sierra-Monsalve, 2015) — logre una posterior materialización y genere vías para su exposición ante un público. La anterior reflexión surge en el marco del proyecto de investigación "Procesos de integración al interior de las prácticas de animación derivadas de la generación de sistemas de artefactura en el diseño de movimiento", que tiene como objetivo general "identificar los elementos técnicos, tecnológicos, prácticos, plásticos, audiovisuales y procedimentales que aportan a la integración de sistemas de artefactura al interior del diseño de movimiento de una producción animada"1 . Particularmente, el presente texto busca:

- Interpretar el uso del cuerpo visto como forma que afecta la actuación proyectada hacia la narración durante la puesta en escena animada, e identificar los principios de animación y segmentación que están relacionados con ésta.

- Identificar los aspectos esenciales para que un animador sin formación actoral profesional aborde los principios y bases de la actuación para la puesta en escena, diferenciando las competencias propias de un actor.

En el marco de esa mirada, se determina que la animación se vale de la observación, análisis y abstracción de las formas en movimiento para generar nuevas interpretaciones de la realidad y lograr la "ilusión de la vida" sobre la materia "inerte" (Buchan et al., 2006). Expresión que es planteada por Frank Thomas y Ollie Johnston en su libro /lusion of Life, en referencia al oficio de la

'El proyecto "Procesos de integración al interior de las prácticas de animación derivadas de la generación de sistemas de artefactura en el diseño de movimiento" se encuentra referenciada con el número 925-18-18 de la convocatoria 18 de creación de la Universidad Jorge Tadeo lozano. 
animación propuesto por Walt Disney como una disciplina que no deja de lado al espectador y, por el contrario, busca que la audiencia se vea involucrada empáticamente con los personajes animados (Thomas y Johnston, 1981).

En relación a lo anterior, afirman Thomas y Johnston (1981) que "Convencer un cierto sentimiento es la esencia de la comunicación en cualquier forma artística" (p. 15). De esta afirmación se desprende que la esencia de la animación es lograr comunicarse por medio de la imagen en movimiento. Para tales efectos, en la producción animada se combinan los oficios manuales (técnicas artísticas), la planificación de un proceso para llegar a un público concreto y la comunicación visual, usando la forma como herramienta empática por medio de la puesta en escena de un personaje para relacionar, envolver e identificar al espectador. Es en esto último que se comparten los procesos de interpretación con el teatro.

Surge entonces el término Acting, entendido desde los procesos actorales, donde un actor es entrenado para usar y apropiarse de los símbolos del lenguaje verbal y no verbal para proyectarlos por medio de su cuerpo. El animador por su parte es el "actor" de las películas animadas, por eso requiere comprender la actuación en su medio con unas intenciones claras para encontrar caminos que logren la transferencia de pensamientos, sentidos, significados y emociones del personaje animado a la audiencia (Thomas y Johnston, 1981). De esta manera, el Acting permite identificar una distinción de la forma corporal como objeto y herramienta de comunicación y creación tanto para actores como animadores.

El nacimiento de técnicas como la animación a partir de imágenes generadas por computador², más conocido como 3D (Laybourne, 1998), permitió a la animación volverse una manifestación de las innovaciones tecnológicas a partir de Toy Story de John Lasseter (Lasseter, 1995), siendo el primer largometraje 
de animación 3D. Posteriormente, el aprovechamiento técnico permite la integración a niveles imperceptibles técnicamente como en Avatar de James Cameron (Cameron, 2009), con su simbiosis entre producción de animación 3D y Live Action (Pikkov, 2010).

Esta simbiosis entre la "producción" y la "reproducción" de imagen en movimiento (Arce, 2014; Linares-Martínez, 2015) se facilita gracias a la tecnología de Motion Capture ${ }^{3}$. Esta tecnología ha permitido que se traduzca el registro del movimiento del cuerpo a mapas digitales ${ }^{4}$ y se puedan a su vez vincular a distintos tipos de personajes sin importar en muchas ocasiones la diferencia de proporción. Aunque con la captura de movimiento MoCap el actor ya puede dirigir la interpretación, solo funciona de manera transparente para animaciones naturalistas en su Acting — como sucede en la captura para las cinemáticas de videojuegos como The Last of Us (Naughty Dog, 2013) o Walking Dead (Telltale Games, 2012)—. En los casos que se requiera un proceso de deformación o ruptura de los cánones corporales, el animador toma este material "mapeado" como primer insumo, para así poder modificar la interpretación del MoCap con el objetivo de evitar una carencia en movimiento y quedar limitado a la capacidad física del cuerpo del actor (Hooks, 2003) (ver imagen 1).

\footnotetext{
3 Captura de movimiento (o su abreviatura en inglés MoCap).

${ }^{4}$ La tecnología de MoCap ha evolucionado mucho a lo largo de los años. Algunos de los más usados son: la captura de información a través de múltiples cámaras que detectan sensores infrarrojos ubicados en el cuerpo del actor, otros usan puntos de alto contraste que son seguidos en programas de rastreo digital, y los más sofisticados usan sistemas de geoposicionamiento digital biométrico a través de sensores giroscópicos.
} 


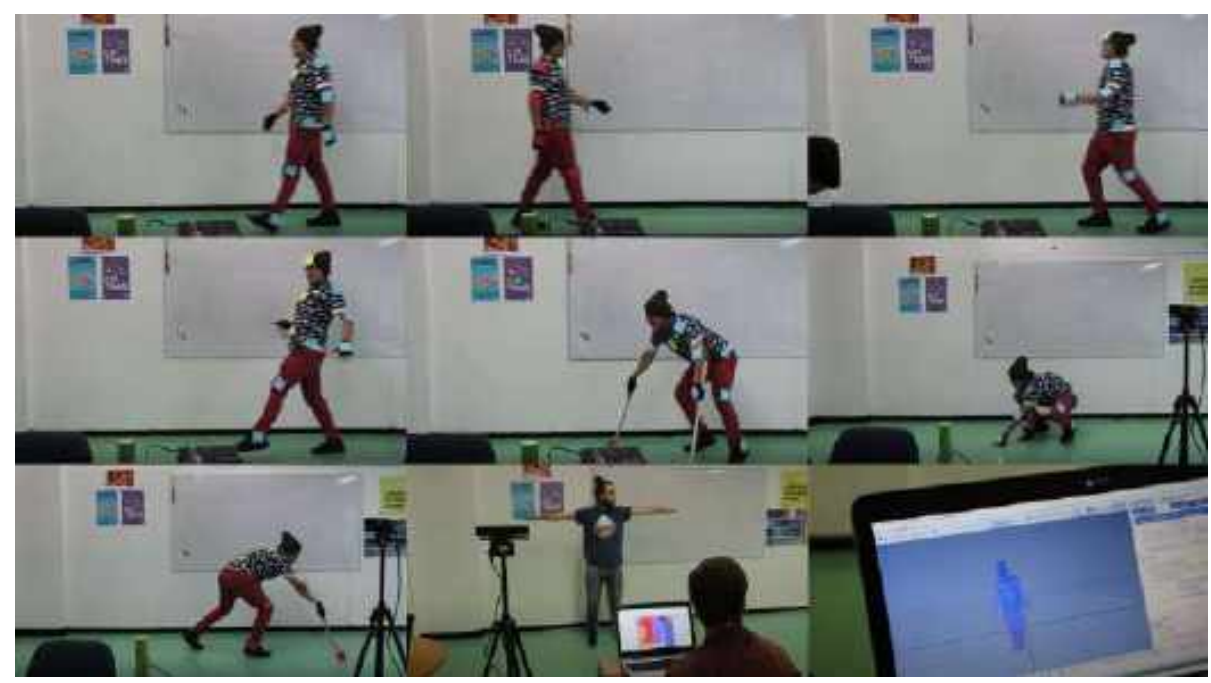

Imagen 1. Ejemplo de trabajo de Mocap con marcadores y Kinects en acciones humanas, bestiálicas y con extensiones.

Fuente: elaboración propia.

La presencia del fenómeno actoral y el registro del movimiento en la animación permiten entonces el estudio de cómo se debe entender el Acting, su apropiación y ejecución al interior de una producción animada. En esta medida, se concibe al Acting como un proceso híbrido de pensamiento y acción, que permite mejorar la creación de sistemas de representación internos (mentales) y externos (icónicos), reinterpretado para responder a una intención simbólica, icónica, narrativa, indicial y testimonial específica de la imagen animada (Durán, 2014), ya sea para proyectar atributos de comportamiento a los personajes animados, o bien como un proceso técnico de registro directo del cuerpo en movimiento para su posterior análisis desde la mecánica (ver imagen 2). 


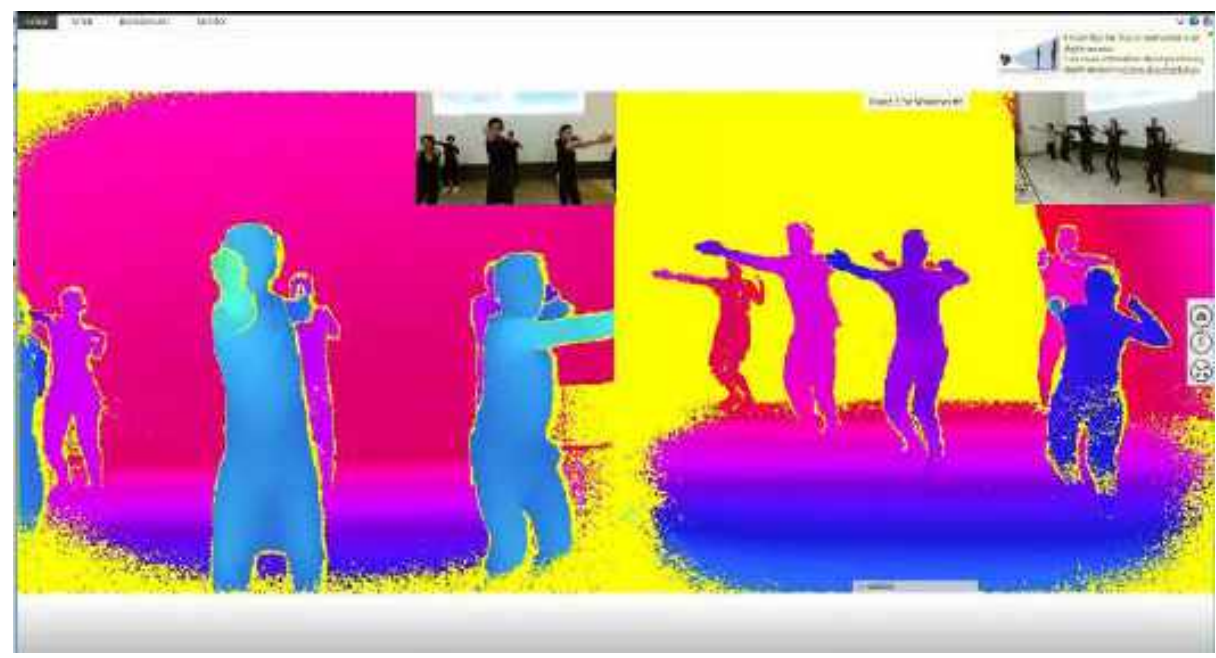

Imagen 2. Captura de ejercicio de biomecánica para lectura de imagen icónica desde la profundidad y el color.

Fuente: elaboración propia.

Partiendo de lo anterior, el Acting se entiende como un medio que permite identificar en el proceso actoral de la animación la forma corpórea en movimiento a manera de objeto de comunicación, aplicada a la interpretación y caracterización que requiere el animador para la construcción de su puesta en escena. En ese orden de ideas, se define forma corpórea como el cuerpo usado a modo de herramienta de comunicación y creación para actores y animadores. En la medida que el cuerpo es visto como herramienta creativa, permite su estudio para interpretar una síntesis corporal a manera de forma activa (o shape ${ }^{5}$ con la capacidad de comunicación. Desde la perspectiva teatral esta idea del shape se puede ver en el trabajo de Meyerhold que

${ }^{5}$ La acepción al anglicismo Shape tiene que ver con la búsqueda de entender la forma desde una percepción gráfica, y que en ese contexto se ha naturalizado dicho concepto para referirse a un elemento elaborado desde el diseño, que comporta un perímetro o silueta, un alto, un ancho y una intención indicial y simbólica. Es decir, el shape en su configuración visual de carácter sintético y abstracto, permite denotar atributos y valores que conllevan connotaciones culturales que generan un proceso comunicativo. 
remite a la forma que se encuentra relacionada de manera directa a la acción biomecánica (Sierra-Monsalve, 2015).

Sin embargo, a pesar de que el cuerpo es un instrumento clave para la narración, es también afectado por principios físicos propios del mundo real, entre ellos el equilibrio, el peso o las leyes de Newton (Halas \& Manvell, 1980). Estos principios físicos influyen en la estructura y segmentación corporal durante la puesta en escena, tanto en la actuación teatral como en la animación. Por ende, se debe identificar qué principios de animación se relacionan entre la representación de propiedades físicas y actitudinales, y la transformación de la forma animada (Thomas y Johnston, 1981) con el objetivo de hacer más viable la transición entre actor, animador y personaje animado, lo que se relaciona con postulados de Stanislavski o Lecoq, quienes plantean una interpretación integral entre forma - intención (objetivo) - motivación - emoción - acción, que le dan al actor la posibilidad de interpretar cualquier tipo de personaje incluyendo animales o cosas además de seres antropomórficos (Sierra-Monsalve, 2015) (ver imagen 3).

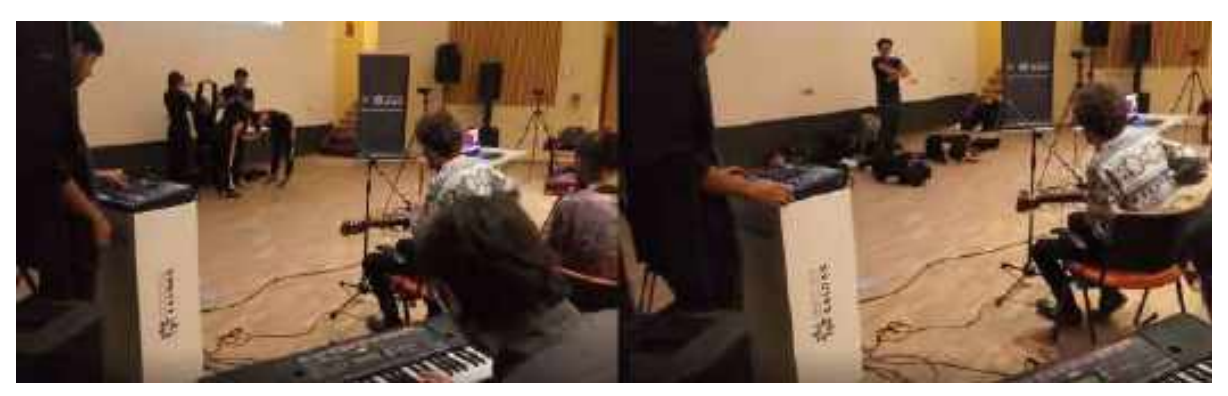

Imagen 3. Ejercicio de interpretación de una escena basada en guion para animación. Fuente: elaboración propia. 
Bajo la anterior premisa, la animación necesita identificar aspectos esenciales de la interpretación para que un animador sin formación actoral profesional pueda abordar los principios y bases de la actuación para potenciar su puesta en escena. Respecto a lo anterior, Hooks enuncia que un animador necesita saber mucho sobre Acting e interpretación, sin embargo, no necesita aplicar todo acerca de estos procesos actorales (Hooks, 2003). Es así como se evidencia la necesidad de diferenciar claramente cómo un animador y un actor usan la actuación según las intenciones de su medio para la posterior obtención de resultados. Lo anterior permite identificar rutas propias de la producción animada para el registro y representación del movimiento derivado de la ejecución en un espacio físico en contraposición a la representación del movimiento generado directa y exclusivamente en un medio digital.

Finalmente, en el texto se busca una exploración mediante la producción de prácticas de animación considerando los hallazgos teóricos previos. Para esto se parte de la creación de material audiovisual donde se tenga registro de las exploraciones interpretativas que se llevan a cabo en el proceso de crear una escena. La abstracción de la forma corpórea identificada en el material audiovisual permite la adaptación al entorno animado y, de esta manera, hacer énfasis en posturas o expresiones del personaje, las cuales por las limitantes del cuerpo humano pueden explorarse gracias a la plástica del cuerpo del personaje animado. 


\section{Contexto histórico}

El hombre desde sus orígenes está acostumbrado a contar historias por medio de imágenes. Contar historias hace parte del ser humano mismo, pues el registro de estas historias es lo que lleva a redescubrir e investigar más sobre la condición humana. La transmisión de mensajes por medio de imágenes y la tradición oral son un medio efectivo para que todo un pueblo sea partícipe (Patmore, 2004). Los chamanes interpretan a los dioses "contando" sus historias para que la tribu las crea. Así evoluciona este ritual desde la antigua tradición oral hasta que la humanidad se asienta en civilizaciones, haciendo que la narración de estas historias evolucione hacia expresiones más sofisticadas posteriormente como el teatro griego (Hooks, 2003). De esta manera, el ritual de reunirse alrededor de una puesta en escena o de una historia significa algo distinto cuando los hermanos Lumière, en diciembre de 1895, organizaron la primera proyección de imágenes en movimiento. Los Lumière, con su Cinematógrafo, usaron la fotografía como medio de capturar el movimiento para entretener (Pikkov, 2010).

De manera similar, Eadweard Muybridge hizo previamente uso de los adelantos tecnológicos fotográficos para también entretener con sus imágenes secuenciadas. Muybridge se interesaba bastante en la captura del movimiento por medio de la fotografía. Se distingue en su trabajo el interés de comprender el cuerpo en movimiento como lo hizo público a través de la famosa apuesta del caballo, momento en el cual queda declarado de manera "explícita" que el ojo humano no logra captar detalles que a través de la tecnología pueden ser evidenciados (ver imagen 4). Entonces se hace evidente que el cuerpo, a través de las fotografías, es objeto de estudio para su entendimiento mecánico y/o expresivo en el tiempo, convirtiéndose así en un pionero en investigaciones de la locomoción del cuerpo humano y animal (Pikkov, 2010). 


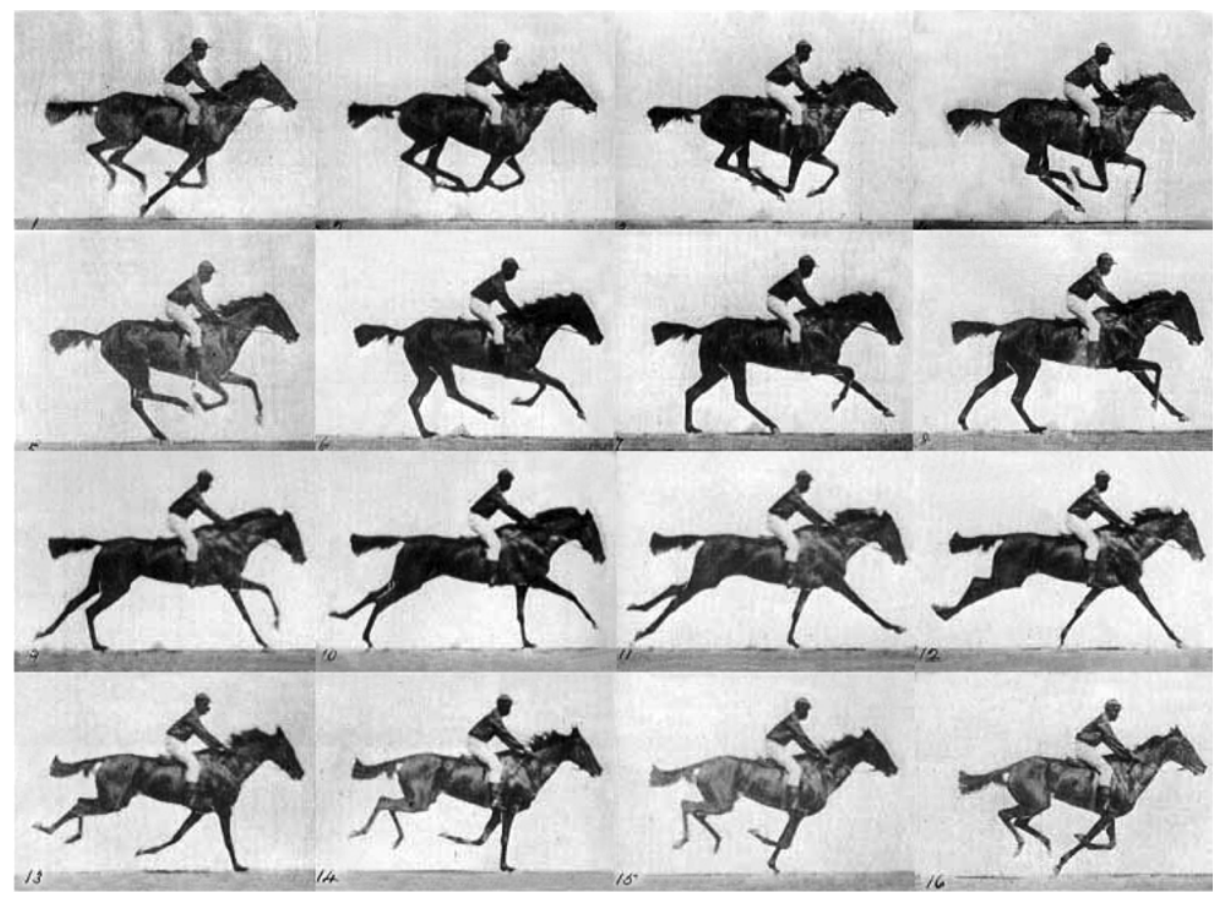

Imagen 4. Caballo en movimiento. Fuente: Muybridge (2010)

El trabajo de Muybridge inspiró de manera similar al Fisiólogo francés ÉtienneJules Marey, quien buscaba representar el movimiento orgánico en formas gráficas para hacer más comprensible el movimiento en una dimensión histórica (Giedion, 1970). El principal interés en el trabajo de Marey es describir el movimiento de los cuerpos en el espacio, desde experimentos iniciales, como el registro en cilindros ahumados de las pulsaciones eléctricas que producía el muslo de una rana, hasta el registro del vuelo de una paloma en 1873 cuando 
empleó su photographic gun. Analizó la ubicación lateral, anterior o posterior individual que hizo Muybridge en sus trabajos, determinando de esa forma que sólo le ofrecían una fase aislada del movimiento.

Marey buscaba una percepción completa del movimiento de manera simultánea en todas sus vistas (Giedion, 1970). Entonces, en 1881 en su casa en París, construyó una instalación ubicando tres cámaras para registrar el vuelo de una gaviota en sus tres ejes axiales (Superior, Anterior y lateral) (ver gráfico 1). Posteriormente, realizó unos diagramas por separado de cada fase dimensional del vuelo, a la par que también elaboró una escultura del ave con todas las poses al mismo tiempo y con su respectivo desfase de movimiento. Esto llevó a un entendimiento del movimiento en el espacio que a simple vista no es fácilmente perceptible. La fascinación que aún produce no es en el registro del movimiento propiamente dicho, si no en la representación del movimiento que obtenía con precisión (Giedion, 1970).

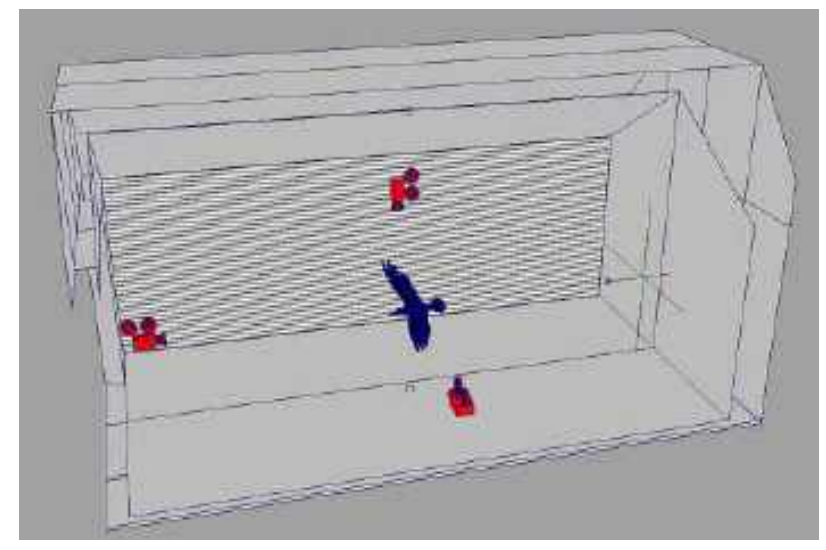

Gráfico 1. Ejemplo de la configuración usada por Marey para captura simultánea de un cuerpo. Fuente: elaboración propia. 
El trabajo de Marey se destaca como pionero debido a la comprensión del movimiento en dos momentos: el tiempo del registro y el tiempo de análisis. El primero de estos momentos implica el dispositivo de captura, así como los artificios para poder parametrizar recorridos, aceleraciones y desaceleraciones, separación de los puntos principales del cuerpo mismo, elementos accesorios de identificación del movimiento, etc. El segundo momento, es decir el tiempo de análisis, se refiere a la revisión crítica de las capturas resultantes separadas del momento del movimiento del ejecutante, en el caso de Marey principalmente fotografías que permiten aislar los puntos de seguimiento ubicados sobre los cuerpos del volumen mismo del ejecutante. Al desplazar el cuerpo sobre fondos oscuros, este tipo de artificios (cintas, bombillos o láminas reflectivas pegadas al cuerpo) permite eliminar el "ruido" del volumen orgánico para la posterior representación gráfica. Esto desarrolló el carácter espacial de su trabajo, sirviendo como referencia y antecedente para los procesos de animación 3D y MoCap.

Para mediados del siglo XX, Giedion expuso extensamente de manera similar el trabajo de los científicos Nicolás Oresme y Frank Gilbreth. Oresme, siendo un obispo francés, fue uno de los primeros y más importantes artífices de la renovación científica medieval en el siglo XIV, en cuyos procesos de abstracción del movimiento hasta su graficación se encuentran los primeros escritos publicados acerca del entendimiento de lo dinámico como concepto por encima de la forma, plasmando la naturaleza del movimiento (ver gráfico 2). 

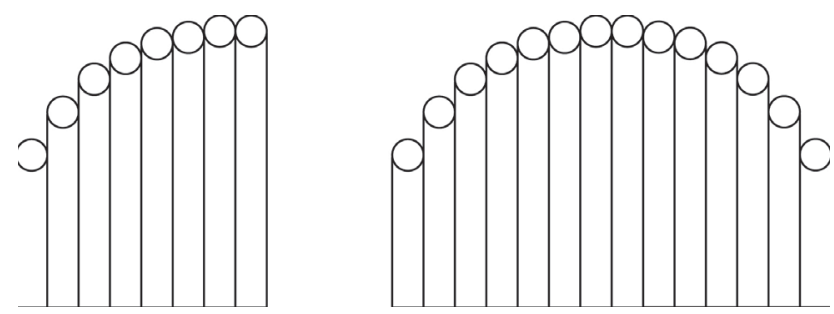

Gráfico 2. Ejemplo de la lógica gráfica de Nicolás Oresme alrededor del movimiento acelerado o desacelerado. Fuente: elaboración propia.

Por su parte, Gilbreth, un ingeniero con plena madurez intelectual a inicios del siglo XX, trasciende el estudio de la ingeniería de los movimientos de los cuerpos a través del estudio depurado de los trabajadores y sus rutinas, recreando sus acciones a través de sistemas de rejillas que recrean cada ejecución para así detectar los errores y optimizar el trabajo. Gracias a la labor de Gilbreth se abren nuevas posibilidades artísticas de formas y valores de expresión para dimensionar la fluidez del movimiento (Giedion, 1970).

\section{Animación como medio de representación}

Los trabajos de Oresme, Muybridge, Marey y Gilbreth destacan en este rastreo histórico, ya que desde inicios de siglo XX hasta hoy la idea de abstracción del movimiento para graficación o, en otras palabras, representación, es un concepto que se enraizó progresivamente en la floreciente industria animada. Este tipo de estudios, derivados en gran parte por el desarrollo del cinematógrafo en 1895 por parte de los hermanos Lumière y la posterior exploración por parte de algunos entusiastas y artistas, lleva de manera casi natural a una experimentación desde el punto de vista de la animación directamente. Es el caso de Zenas Winsor McCay (1869-1934), dibujante de comics que utilizó el artificio del trucaje óptico en sus dos reconocidas producciones, 
Little Nemo (McCay, 1911), en la que el personaje Nemo lograba movimiento en un punto de la reproducción, y Gertie, the Dinosaur (McCay, 1914), que parecía interactuar naturalmente con McCay (Wikoff, 2009). Este soporte técnico también fue aprovechado por Émile Cohl (1857-1938), considerado el primer animador a tiempo completo y quizás el más importante hasta 1915. Hizo la primera película de dibujos animados Ilamada Fantasmagorie (Cohl, 1908), al igual que la primera serie de animación adaptación del cómic de George McManus, The Newlyweds (Cohl, 1912). Fue uno de los más inquietos exploradores del medio usando todo tipo de técnica de animación posible en su momento (Alvarez-Villanueva, 2007; Lorenzo-Hernández, 2020)con una evolución oscilante, ha demostrado ser una baza importante en el negocio cinematográfico. Desde el punto de vista de las metodologías de análisis del discurso cinematográfico, la introducción de las nuevas tecnologías en este ámbito ha supuesto la posibilidad de ampliar los formatos de representación del lenguaje discursivo. Su público no es únicamente infantil o familiar, sino que con dicho tipo de películas se tratan contenidos de lo más diversos orientados también a adultos. El cine de dibujos animados consiste en el uso de una gramática fílmica compleja con el objetivo de crear personajes, decorados y paisajes. Para llevarlos a cabo, es necesario un trabajo de equipo en el cual la realización de cada uno de los elementos de la producción (personajes, guión y montaje (ver imagen 5). 


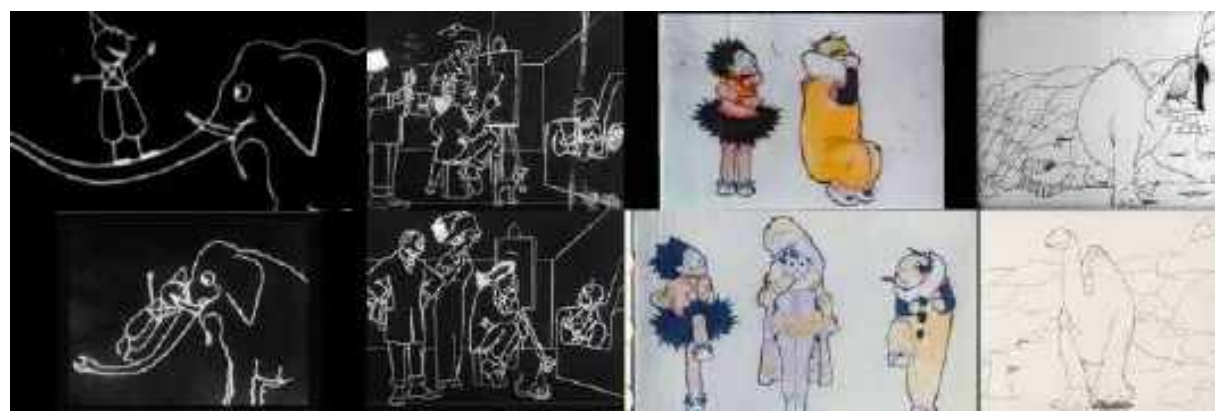

Imagen 5. Fotogramas de las obras de McCay y Cohl. Fuente: Cohl (1908, 1912); McCay (1911, 1914).

Esta idea de representación fue algo que Walt Disney empleaba para generar su "Ilusión de la vida". Los 12 principios de animación descritos por Thomas y Johnston fueron conceptos en desarrollo derivados de la observación y la práctica, que posteriormente fueron nombrados dentro de la jerga del animador para el desarrollo de movimientos creíbles por medio una comunicación clara (Thomas y Johnston, 1981).

Para llegar a este proceso de representación, los primeros esbozos de una industria animada en Norteamérica llegaban a recurrir a material filmado con actores que recrearon las escenas que posteriormente conformarán la película animada. De esta manera, el término Live Action ${ }^{6}$ surge en animación inicialmente para referirse al material filmado para la planeación y ejecución de escenas animadas, cuyas acciones fueran difíciles de captar y/o como apoyo para los animadores. Thomas y Johnston (1981) afirman: "El Live action puede dominar al animador, o le puede enseñar" (p. 319). La interpretación del material Live Action permitía desarrollar la escena a pesar de que las actuaciones

${ }^{6}$ Cuando se refiere al concepto de Live Action se refiere a la "acción en vivo" que es filmada con la actuación de seres humanos, quienes interpretan a los personajes bajo una dirección de escena. 
fueran crudas, sirviendo de guía para el animador ayudándole a pensar en cómo potenciar la escena según los personajes, siendo una oportunidad para pulir la misma (Thomas y Johnston, 1981).

En la época de Walt Disney, una vez terminado el proceso de rodaje, se pasaba a un proyector denominado Rotoscope Machine. Sin embargo, con los avances de la época se logró imprimir los fotogramas de las filmaciones, Ilamados Photostats. En este punto se aprovechaba que los fotogramas exponían un rango de movimientos a velocidades superiores a las que el ojo humano podía detectar muy similar a los trabajos evidenciados de Marey y Gilbreth. Al usar Photostats se requería transformar la estructura del cuerpo humano registrado en formas que pudieran ser animadas (Animatable shapes) (ver imagen 6), siendo estas formas sus herramientas principales para comunicarse. Las adaptaciones de las formas consideraban la estructura corporal que tenía el diseño del personaje. De esta forma la acción a representar permite la adición de rasgos actitudinales y expresivos durante el movimiento. La forma animada se basa entonces en la forma corpórea en cuanto a manejo del tiempo durante la puesta en escena (timing \& staging) (Thomas y Johnston, 1981). 

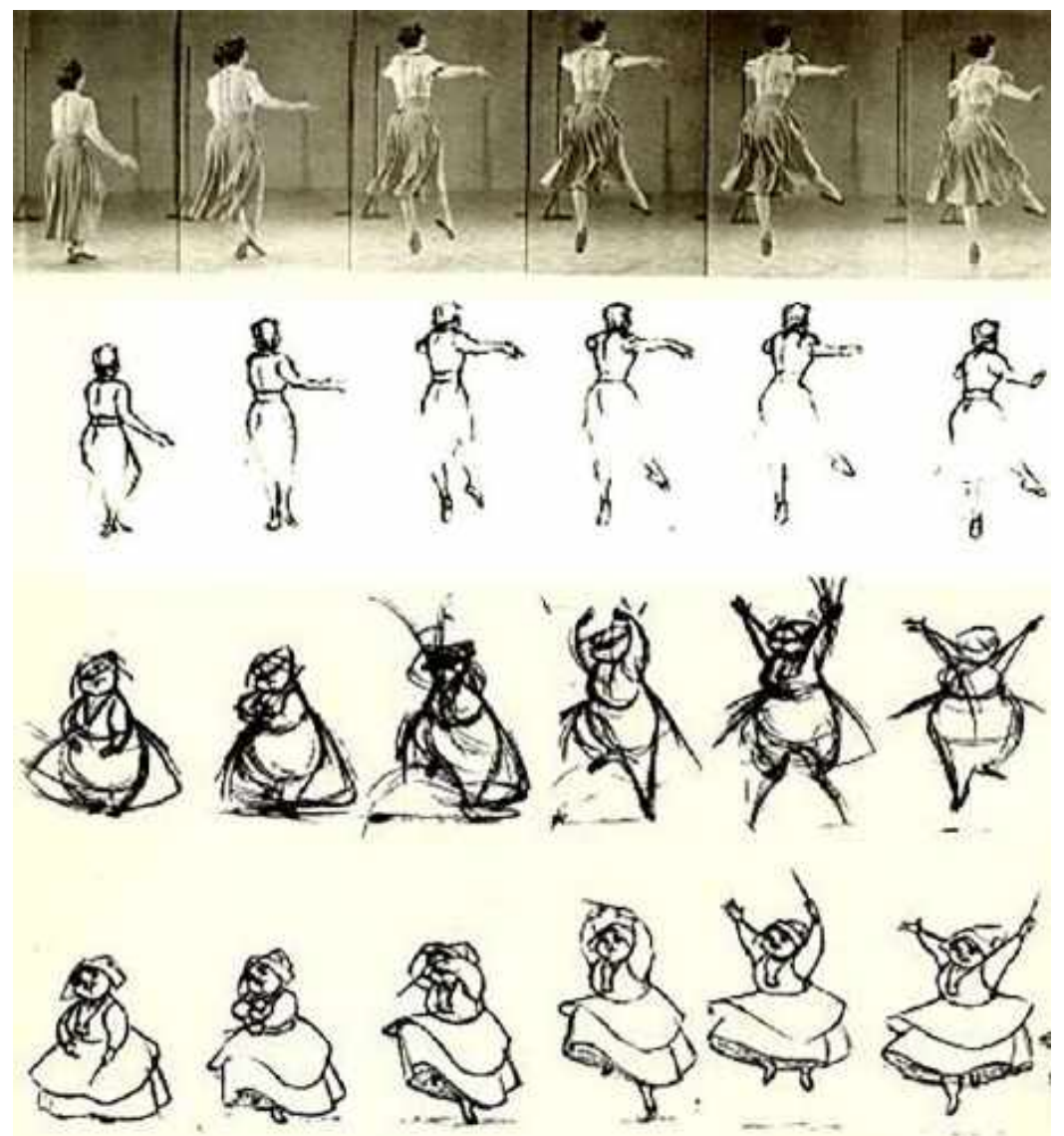

Imagen 6. Photostats \& animatable shapes, Actriz: Helene Stanley, Animator: Frank Thomas para Sleepy beauty. Fuente: Thomas y Johnston (1981).

Para total claridad, Thomas y Johnston explican que llegaron a comprender que el movimiento no se podía copiar directamente del material o rotoscopiar 
de manera idéntica el movimiento, pues el resultado era algo que se percibe muy similar al material "real" haciendo perder a los espectadores la "Ilusión de la vida" (Thomas y Johnston, 1981, p. 322). Al referirse al término "perder la ilusión de la vida" se hace relación a las palabras de Patmore que la define como "La suspensión de la incredulidad" (Patmore, 2004, p. 14). Patmore explica lo anterior refiriéndose a que la forma en que se presenta y el cómo presenta el personaje es lo que permite que la audiencia olvide, por un lapso de tiempo, el hecho de estar viendo un montón de dibujos y empiece a reconocer al personaje puesto en escena.

Hooks también plantea este concepto de la ilusión de la vida y suspensión de la incredulidad en un apartado de su libro Acting for animators. Hooks enuncia que las elecciones que hace el animador están pensadas para que la interpretación del personaje deba contar los puntos más importantes de la historia y de esta manera logre que el espectador empiece a involucrarse con lo que está viendo, sin entrar en un estado de desconcierto. La suspensión de la incredulidad ejemplificada por Hooks se relaciona adicionalmente con la representación y estilo de las formas en la animación, desde el estilo Cartoon o estilizado hasta la animación Fotorrealista. Los espectadores no se cuestionan que las leyes y fuerzas físicas afecten a personajes Cartoon de una forma poco convencional a como en verdad funcionan en el mundo real, a diferencia de la connotación de éstas en un personaje fotorrealista (Hooks, 2003).

Ampliando el concepto de suspensión de la incredulidad, Pikkov hace referencia al concepto del "valle misterioso" de Masahiro Mori, ingeniero japonés diseñador de robots e inteligencia artificial. Mori explica que los cuerpos artificiales como robots o personajes animados pueden generar un sentimiento de repulsión en vez de empatía cuando su artificialidad se vuelve "demasiado humana". El humano se identifica con los personajes 
animados debido a que en un nivel inconsciente reconoce códigos de comportamiento (Pikkov, 2010).

\section{El cuerpo como herramienta para la representación}

En su libro Animated Worlds (2006) Buchan et al. hace una analogía entre el oficio del animador y el oficio de un titiritero o "maquinista" (como ella lo denomina), recordando que a diferencia del cine de acción en vivo (Live Action), la animación se caracteriza porque no cuenta con cuerpos, objetos o personajes vivos que tengan la capacidad de moverse sin manipulación alguna cuando son filmados. Basado en el texto de Heinrich Von Kleist On the marionette theatre, se expone por qué se considera a la marioneta como un ser animado, tomando en cuenta que su alma no es una entidad psicológica si no una fuerza de movimiento que crea la ilusión de tener voluntad propia, remarcando el hecho de que la marioneta es dotaba de su alma gracias a la voluntad y movimientos que el maquinista ejerce sobre el cuerpo de la marioneta (Buchan et al., 2006).

Considerando lo anterior y la naturaleza técnica detrás de la ilusión que genera el maquinista sobre su marioneta, se permite entonces esta relación en lo que implican las fuerzas que el animador ejerce sobre su cuerpo animado, en donde ya no hay movimiento producido por hilos necesariamente. El reemplazo del modo de operación tiene como resultado la exclusión de la naturaleza humana, ya que en la animación el agente de movimiento y la fuerza operativa se mantiene invisible. La destreza del animador se encuentra en generar específicos arreglos en la configuración y escultura del cuerpo animado de cada fotograma, para que al final la reproducción de los fotogramas permita la ilusión de que el cuerpo animado se mueve por voluntad propia (Buchan et al., 2006). 
"El efecto de voluntad autónoma" es otra forma de entender la expresión "la ilusión de la vida" de Thomas y Johnston, basada en las ideas de Buchan et al. (2006) que explica la producción de cuerpos "vivos". En este sentido, se parte de una realidad fabricada por procesos técnicos y meticulosos de creación de movimiento, donde la materia inanimada es dotada de vida con el fin de establecer un estado epistemológicamente producido por el movimiento corporal y donde los cuerpos se vuelven inteligibles y/o comprensibles; lo que Buchan et al. definen en su texto como Animacy en referencia al "estado de ser animado" (Buchan et al., 2006, p. 50-60).

\section{Acting o actuación}

Entendiendo su definición, traducción y significado léxico, evidentemente Acting no traduce "actuación" como oficio o disciplina, sino acción de la interpretación. Esto aterriza y da indicios de su uso en el campo de la animación. Según el diccionario de Cambridge, Acting se traduce como interpretación: "the job of performing in plays or movies" (Cambridge, 2017), es decir, el trabajo de interpretar o representar en una puesta en escena o película. De igual manera la Real Academia Española (RAE) define Actuación como: "1. f. Acción y efecto de actuar" a diferencia de la palabra interpretar que presenta dos definiciones "4. Tr. Concebir, ordenar o expresar de un modo personal la realidad." y "5. Tr. Representar una obra teatral, cinematográfica, etc." (Real Academia Española, 2017).

Acting (acción para la interpretación) en la animación empieza a ser un recurso para generar escenas con más poder comunicacional. En este proceso de pasar del acto de interpretar a la animación del personaje animado, el animador previamente establece la justificación de las formas "animables" (posibles de animar) como los insumos para la comunicación, facilitando la percepción e identificación con el espectador. El animador con estas formas construye a sus 
personajes y sus posibles interpretaciones, a la vez que adaptando la forma humana a sus propios diseños les atribuye espíritu y vida. Aun con posibilidad de representar el movimiento de una manera realista, se necesita entonces ser selectivo y personalizar aquellas acciones que se quieren enfatizar para una escena (Thomas y Johnston, 1981).

La tarea del animador en este caso es potenciar posibles interpretaciones de una escena resaltando puntos claves para contar la historia. Como se mencionó anteriormente, el uso de las referencias del video en Live action busca que el actor agregue características físicas a su interpretación para enfatizar sus actitudes corporales durante la misma. Por eso, un mismo actor no debe interpretar a más de un personaje durante el rodaje de una película. De ese modo la animación requiere agregar los atributos actorales al oficio de diseño de movimiento, para así lograr una mejor caracterización del personaje y que la audiencia se involucre más con las historias (Thomas \& Johnston, 1981).

La interpretación es asumir roles, cosa que se hace todo el tiempo, indica Richard Williams en su libro The Animator's Survival Kit. El ser humano nunca asume un mismo comportamiento todo el tiempo en todo lugar, depende de situaciones que hacen variar su comportamiento y actitud. El darse cuenta de estas interpretaciones y actitudes, a partir de la observación y de la experiencia, amplía el rango emocional para asumir una mayor cantidad de roles (Williams, 2001). La construcción de un amplio rango emocional es lo que se convierte en material interpretativo para proyectar dichas emociones en los personajes que está representando. El fin no es actuar únicamente, sino que se necesita personificar el personaje para sentir las emociones y magnificar el resultado, pues la interpretación permite hacer más profunda y enriquecedora la escena. Cautivar y entretener a la audiencia con la puesta en escena es el objetivo de la animación (Williams, 2001). 
El personaje debe mostrar control de sus acciones y verosimilitud en el mundo en el cual se desenvuelve, para esto, el desarrollo de la personalidad del personaje afecta su interpretación y movimiento. Hooks, Goldberg y Williams resaltan el factor de conocer a profundidad al personaje para su construcción. Goldberg resalta que el personaje debe mantener una congruencia en la producción de una escena; la exploración de emociones y gestos debe ser responsable para evitar una pérdida en la esencia del personaje (Goldberg, 2008).

En Acting for animators de Ed Hooks se señalan conceptos para la interpretación, los cuales se pueden condensar en una construcción de la interpretación a partir del pensamiento. Esto quiere decir que el pensamiento conduce a emociones y las emociones conducen las acciones del personaje. Una cadena de mando que permite entender y desarrollar de mejor forma el personaje, logrando un manejo de tal manera que el personaje esté en control y reaccione a estímulos (Hooks, 2003). Además de lo anterior, Eric Goldberg expresa como el Acting juega un rol predominante en la audiencia, ya que es la interpretación la que permite visualizar que el personaje está en control y puede reaccionar a estímulos emocionales o físicos. La animación debe evidenciar en el personaje su personalidad, particularidades físicas, expresiones faciales, además de las fuerzas de gravedad y peso (Goldberg, 2008).

Tomando en cuenta estas tres posturas alrededor de la interpretación, se puede plantear entonces que la concepción del movimiento y construcción de la puesta en escena son distintos para el actor que para el animador (Hooks, 2003):

- Actor: por medio de la presentación corporal directa y el hacer en escena concibe el movimiento de adentro hacia afuera. Las acciones que ejecuta son visualizaciones de metas e intenciones mas no necesariamente de procesos. Es por eso que sus interpretaciones no siempre son las mismas 
a pesar de ser preparadas muchas veces con anticipación o ensayadas coreográficamente.

- Animador: por medio de la observación y discusión concibe el movimiento de afuera hacia adentro. Busca un entendimiento motriz inicialmente para la construcción e interpretación de resultados aplicados a un tercer "cuerpo", pues necesita analizar los mejores movimientos para favorecer sus intenciones narrativas de manera muy calculada.

A pesar de tener diferencias contrastadas, tienen las mismas metas y objetivos de representación y comunicación por medio de una realidad teatral. Hooks presenta este concepto en donde la realidad presentada no busca ser una copia de la realidad. Esta realidad es construida en un tiempo y espacio condensado, diseñado para generar el mayor impacto posible a quien lo vea. La construcción de un reflejo de la realidad permite resaltar y enfatizar en rutas apropiadas para la comunicación con la audiencia a través del movimiento, a diferencia de una realidad que deja pasar todo sin ninguna clase de filtro (Hooks, 2003).

La representación en la realidad teatral la comparten tanto animador como actor, sin embargo, el concepto de puesta en escena determinados por el espacio y el tiempo son completamente distintos. La actuación sucede en el momento presente cuando es capturado o ejecutado, es por esto que Hooks ejemplifica que, si un actor de cine tuviera que hacer 20 veces la misma toma, esas veinte veces la actuación sería distinta. La puesta en escena para un actor lo lleva de una acción a otra acción, una emoción a otra emoción, y su interpretación es única, impidiendo una reproducción exactamente igual. Por otro lado, el animador no cuenta con un tiempo presente, incluso si utiliza el video referencia como recurso, debido a que la utilidad de la referencia no es para el momento presente sino para uno futuro, cuando se quiera abstraer la imagen. Se sabe que la representación del movimiento puede consumir mucho más 
tiempo puliendo y enfatizando en los movimientos corporales o expresiones faciales adecuadas con el fin de concebir un movimiento convincente y creíble, aunque al final, una vez creada la interpretación del personaje animado, este andará por su cuenta en su perfomance (Hooks, 2003).

La discusión de la interpretación no física que el animador debe pensar y representar, quizá fue lo que llevó a la creación del principio del Staging. Thomas y Johnston lo describen como el principio que lo abarca todo, debido a que la puesta en escena en la imagen animada involucra: composición de la imagen, el espacio, el equilibrio, puntos de tensión, y el ángulo o posición de la cámara. Considerando los atributos que maneja, su función principal es que la exposición de una idea sea clara en su totalidad, con acciones legibles y entendibles, haciendo uso de expresiones que evidencian una personalidad reconocible (Thomas y Johnston, 1981). Es así como el Acting se combina con el Staging.

En este punto se deben entender los principios de animación como conceptos que permiten abordar y representar el movimiento de una manera práctica y gráfica, sin embargo, no son leyes del movimiento. La presencia escénica es un concepto que Sergio Sierra Monsalve maneja en sus tesis de doctorado (2015), la cual gira en torno al principio de alteración del equilibrio. Este concepto implica una manipulación de la tradicional verticalidad de los sujetos, sacando su eje de balance y generando una condición "dinámica" que atrapa al espectador en un proceso de tensión entre lo conocido como estable y lo esperado a desarrollar de manera desconocida por el público.

La presencia escénica, igual que la animación, cuenta con sus principios, y tiene técnicas o normas para potenciar la existencia del actor en escena. El trabajo de Sierra-Monsalve se enfoca en las representaciones del arte escénico moderno, buscando cómo el principio de alteración del movimiento se ve involucrado 
como herramienta metodológica que busca potenciar el espectáculo artístico desde el movimiento físico del actor (Sierra-Monsalve, 2015). Sierra-Monsalve retoma el principio de alteración del equilibrio, propuesto por Barba, como uno de los principios bases para los artistas de escena o actores, el cual busca el abandono de un equilibrio cotidiano a favor de un equilibrio extraordinario; este es el que permite a lo largo del cuerpo generar fuerzas y tensiones físicas.

El cuerpo ya se encuentra en un estado vivo incluso antes de su presentación, por medio del desplazamiento del centro de gravedad de la línea central del cuerpo, o por medio de aprovechar la plasticidad limitada que da el cuerpo humano. Este tipo de presencia escénica se soporta en la concepción de Barba acerca de la antropología teatral. En su propuesta rescata al cuerpo como centro de la escena y al movimiento como técnica, obligando al actor a ser consciente de la necesidad de una ajustada interpretación psico-física para capturar al espectador a través de la verosimilitud con el contexto narrativo que lo rodea (Sierra-Monsalve, 2015).

Sierra-Monsalve cita en su tesis a Eugenio Barba, autor de la Antropología de la teatralidad, entendiendo el cuerpo como una herramienta que se usa en determinados momentos de representación, Ilegando a lo que Barba define como un tiempo ordinario y un tiempo extraordinario. Entender los dos estados del cuerpo como herramienta, permite generar un fundamento teatral y escénico que permite la comprensión del comportamiento escénico. Es decir, en una representación organizada, la presencia del actor se transforma con los conceptos teatrales pasando de un cuerpo en estado ordinario a uno en estado extraordinario que en forma una unidad del cuerpo y la mente (Sierra-Monsalve, 2015).

El uso de principios como el peso, el equilibrio, el uso de la columna vertebral y los ojos mantienen al cuerpo escénicamente vivo o creíble, haciendo sentir 
la presencia del actor. Barba nombra estos principios como: "Los principios de pre-expresividad", a partir de los análisis que hace del teatro oriental y algunas técnicas en occidente como la del mimo o la del ballet europeo, en la ISTA ${ }^{7}$ los comprueba. A grandes rasgos, la creación de la escuela fue para reunir en la práctica del movimiento diferentes técnicas y formas de comportamiento de los actores y bailarines, quienes a pesar de sus diferencias culturales demostraron que de diversos modos siempre utilizaban los mismos principios (Sierra-Monsalve, 2015); son tres fundamentales: el principio de alteración del movimiento, el principio de oposición y el de coherencias incoherentes. Barba se apropia de estos principios definiendo un estado en el que los principios físicos ayudan a la comunicación teatral. La pre-expresividad para Barba es un estado mental y físico donde el actor se predispone en función de proyectar sus intenciones incluso mucho antes de entrar en escena. Haciendo una analogía a este concepto, el animador empieza a concebir el movimiento mucho antes de su hacer técnico, así es como el Acting se puede emplear como un medio inicial para que el animador personifique o encarne a su personaje mucho antes de entrar al proceso de animar (armaturas, dibujos o software).

El estado pre expresivo permite en mimos, actores, bailarines, y en este caso animadores, un espacio para la generación de posibilidades y en donde la exploración es una herramienta para la creación de variables actitudinales, narrativas y físicas para la optimización de la interpretación. Siendo el principio de alteración del equilibrio uno de los principios pre expresivos principales, Sierra-Monsalve cita del diccionario de la antropología teatral conceptos como el contrapeso, la línea, el centro de gravedad y el tono muscular. Estas son implicaciones físicas que permiten la construcción del cuerpo teatral, el cual es el que hace transferencias de intenciones físicas o mentales a su personaje para que se manifiesten en su cuerpo (Sierra-Monsalve, 2015). 
Sierra-Molsalve define entonces que el cuerpo funciona a manera de herramienta, aunque no hace cuestiones sobre el estado real o la forma en que dicho cuerpo puede ser configurado para una puesta en escena enmarcada en otra naturaleza diferente al teatro. Pero con el repaso de los maestros del teatro moderno, sí se pueden determinar formas de abordar y usar el cuerpo con otros tipos de intenciones según el autor que se esté consultando, con el fin de crear relaciones entre la interacción del principio de alteración del equilibrio con el trabajo y metodología propuestos por maestros como Stanislavski, Meyerhold, Laban, Decroux, Lecoq y Grotowski (Sierra-Monsalve, 2015) (ver gráfico 3).

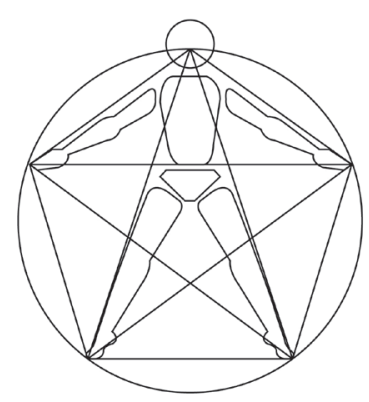

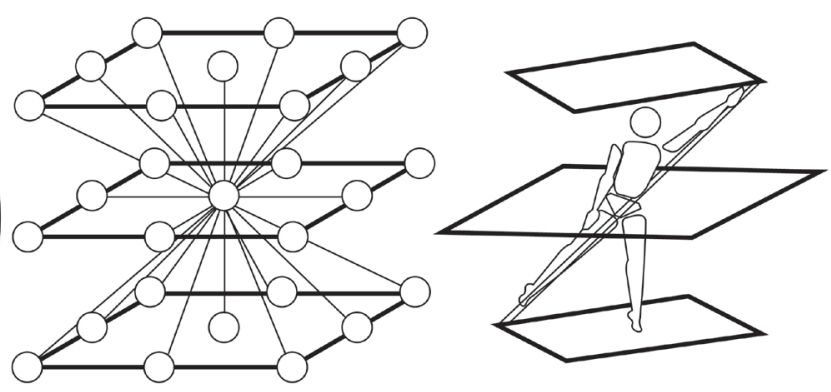

Gráfico 3. Sistema espacial de Laban para el movimiento corporal. Fuente: tomado del libro "Choreutics" de Rudolf Laban (1966).

El estudio que plantea Sierra-Monsalve, comparando transversalmente estos maestros teatrales, señala cómo la necesidad de una consciencia corporal facilita el desarrollo de su puesta en escena, el equilibrio se vuelve un aspecto físico fundamental para la estructuración del cuerpo a través de la escena ya que se enlaza con el peso, la línea de acción, el centro de gravedad, la estructura corporal y la inercia. Como animadores, la representación del movimiento implica entender la naturaleza anatómica y mecánica que permite explorar con mayor libertad las posibilidades interpretativas y escénicas. 
Por lo anterior el lenguaje corporal, tanto para animación como para la actuación, relaciona el cuerpo y sus segmentos con el espacio, permitiendo una comunicación efectiva. Autores como Hooks, Goldberg, Williams, y Frank y Thomas, resaltan la importancia del lenguaje corporal como punto común cuando se habla de Acting. Entender el valor estructural del personaje, su contexto y atributos físicos permite la creación de gestos y movimientos sinceros convincentes, claros y apropiadamente motivados (Thomas y Johnston, 1981).

El lenguaje corporal trae consigo la "pantomima", concepto abarcado por los autores mencionados anteriormente. Williams define la pantomima como el arte básico de la animación (Williams, 2001). Adicionalmente Hooks resalta el valor que tiene contar todo en una escena a través del cuerpo, sin ninguna clase de diálogo donde este se vuelve un elemento adicional que potencia la interpretación, pero que por medio de unas poses cuidadosamente planeadas se pueden entender puntos claves de la historia, dejando en claro intenciones, motivaciones, acciones y, finalmente, emociones (Williams, 2001). La importancia de la construcción de poses con actitud se debe a que por medio de ellas se puede dar una idea temprana de cómo se siente la interpretación a través del cuerpo, ayudando a determinar la fluidez y contundencia en las poses a partir de aspectos físicos, resaltando el peso, la línea de acción y los centros de poder (Goldberg, 2008).

Finalizando, el Acting en la animación puede ser entendido como el acto de interpretación de un personaje. La planeación del movimiento en una escena se debe hacer a través de una disección temporal de la acción en dos etapas, la primera siendo el momento del registro, y la segunda el análisis y representación del movimiento. Al tratar una escena, el Acting es un modo de exploración para saber qué buscar en la interpretación, enfatizando en la actitud corporal o gestos que se quieren proyectar en el personaje. La construcción de la personalidad se evidencia con el proceso de pensamiento, determinando el 
cómo y el porqué de su comportamiento, la búsqueda de cualidades internas y externas, permitiendo rasgos de personalidad que se manifiestan en atributos actitudinales y de comportamiento.

\section{Metodología}

La investigación es de corte cualitativo, empleando técnicas de observación y experimentación que pueden revelar resultados para contrastar con el marco teórico expuesto. Se desarrolló un trabajo de campo con el que se buscó experimentar un proceso actoral no profesional y la producción de prácticas de animación que abarcan un trabajo más extenso.

Para efectos de la investigación se buscaba la construcción de un movimiento creíble, empático con el público, el cual se concibe a través del concepto del viaje (journey), la identificación y la transferencia, propuestos por Lecoq en su obra "El cuerpo poético" (2003). Al identificar todo tipos de formas, desde las más biológicamente correctas hasta las más fantásticas, se puede llegar a construir cualquier tipo de intención y personaje, como un resultado de las transferencias que se hacen entre situaciones, ideas, formas y componentes que terminan siendo adaptadas al cuerpo animado a manera de máscara que puede tomar cualquier tipo de comportamiento que se desee y que posteriormente es visto a través del sistema de representación en el que se está captando el movimiento.

El diseño de movimiento se visiona entonces como un proceso de planificación que involucra narrativas y artefactos ideológicos con una intención específica, proyectados a una acción concreta la cual aplica un esfuerzo mediado por elementos mecánicos y plásticos, desarrollándose en el espacio mediante el entendimiento y manipulación del ritmo y el tiempo, buscando a través del viaje del animador, generar el appeal del movimiento proyectado (ver gráfico 4). 


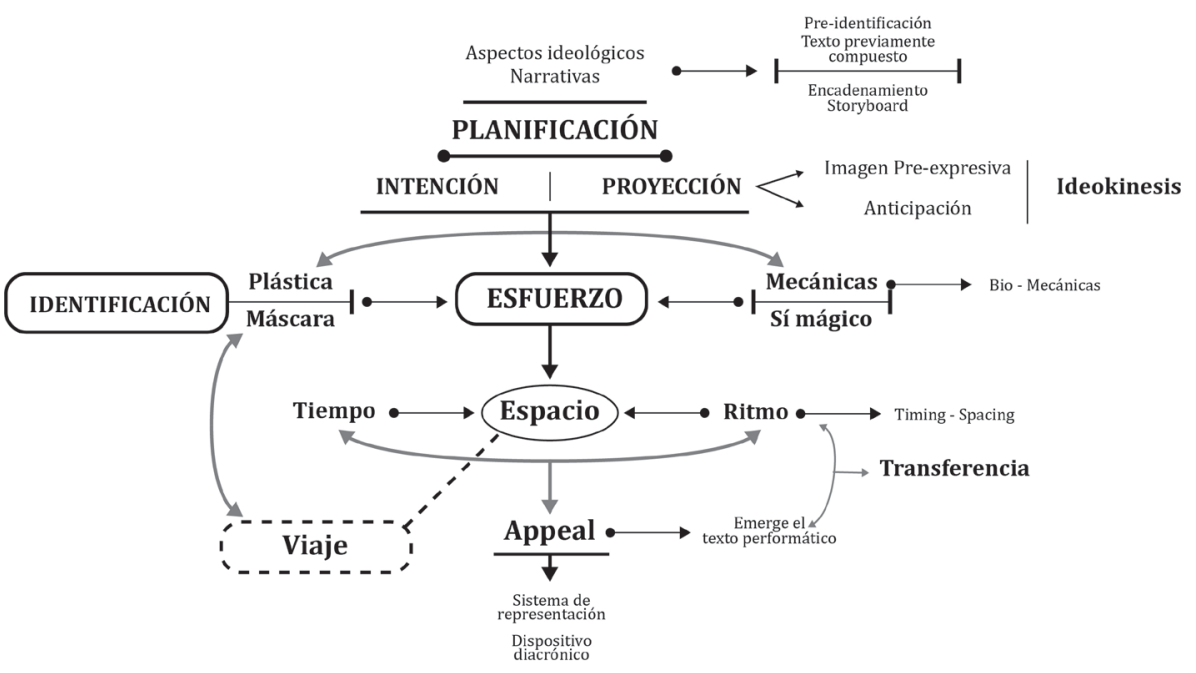

Gráfico 4. Esquema de características y tensiones del diseño de movimiento Fuente: elaboración propia

\section{Producción de escenas}

Bajo la técnica de experimentación y realización de escenas animadas se quería determinar el papel del Acting dentro de unos espacios y tiempos de producción, siguiendo protocolos aprendidos en los espacios académicos y comparándolos con el marco teórico consultado para este proceso. La planeación y elección de personajes determinaron entonces la construcción de la escena y el flujo de trabajo a manejar.

Se realizaron diferentes tipos de ejercicios, algunos con animadores del semillero de Diseño de Movimiento de la Universidad Jorge Tadeo Lozano interpretando emociones y aplicando algunos conceptos básicos actorales, para 
definir elementos a tener en cuenta y que fueran evaluados por profesores de artes escénicas para determinar su calidad y nivel de apropiación (ver imagen 7). De manera paralela, se interpretó una escena de un guion para animación, parte del proyecto con los estudiantes del semillero de Diseño de Movimiento Físico del programa de Artes Escénicas de la Universidad de Caldas. Estos generaron una partitura de interpretación de la escena que fue revisada y analizada para buscar los énfasis, las diferencias en el abordaje y esencialmente identificar los aspectos principales que pueden alimentar la correlación entre animador y actor para desarrollar elementos propios e inequívocos de un personaje (ver imagen 8).

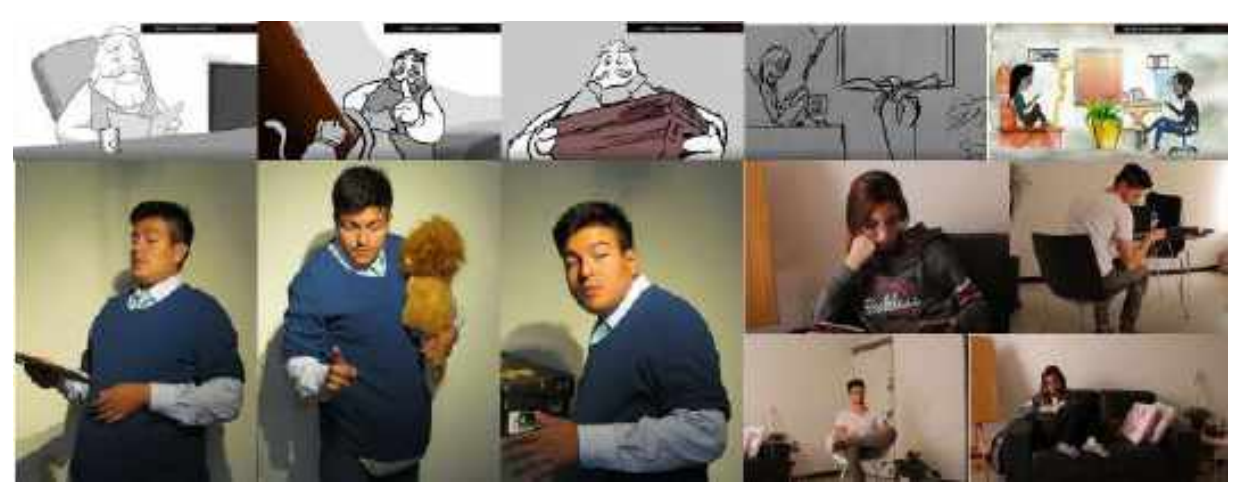

Imagen 7. Prácticas de Acting partiendo de animatic y guión de propuesta de corto "Amanecer". Fuente: elaboración propia. 


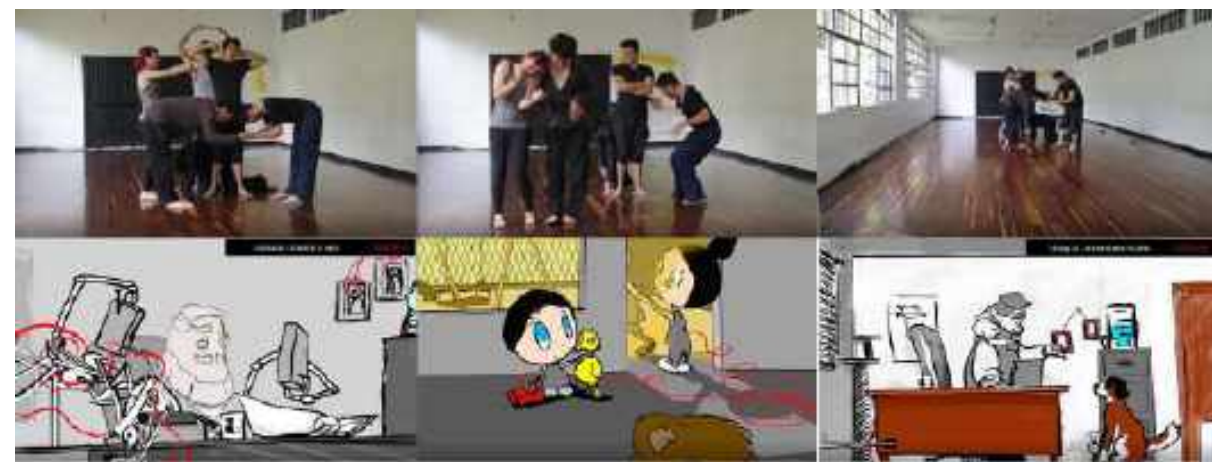

Imagen 8. Interpretación por parte de estudiantes de artes escénicas de animatic y guión de propuesta de corto "Amanecer". Fuente: elaboración propia.

Una vez se identificaron los aspectos más relevantes en el proceso de interpretación, se buscó trasladar estos elementos a la articulación en un flujo de producción de un personaje animado en CGI. Se analizaron cuáles eran las diferentes etapas de producción, su relevancia y dimensión en el marco del proyecto, así como su pertinencia para los fines no solo de la investigación, sino que pudiera ser funcional en los procesos de capacitación para futuros animadores, así como para los proyectos animados relacionados con el semillero de investigación Diseño de movimiento.

El personaje seleccionado para el proceso de prácticas de animación fue el siguiente:

Atributos formales: Animal estilo cartoon, Antropomorfo orgánico (ver imagen 9). 


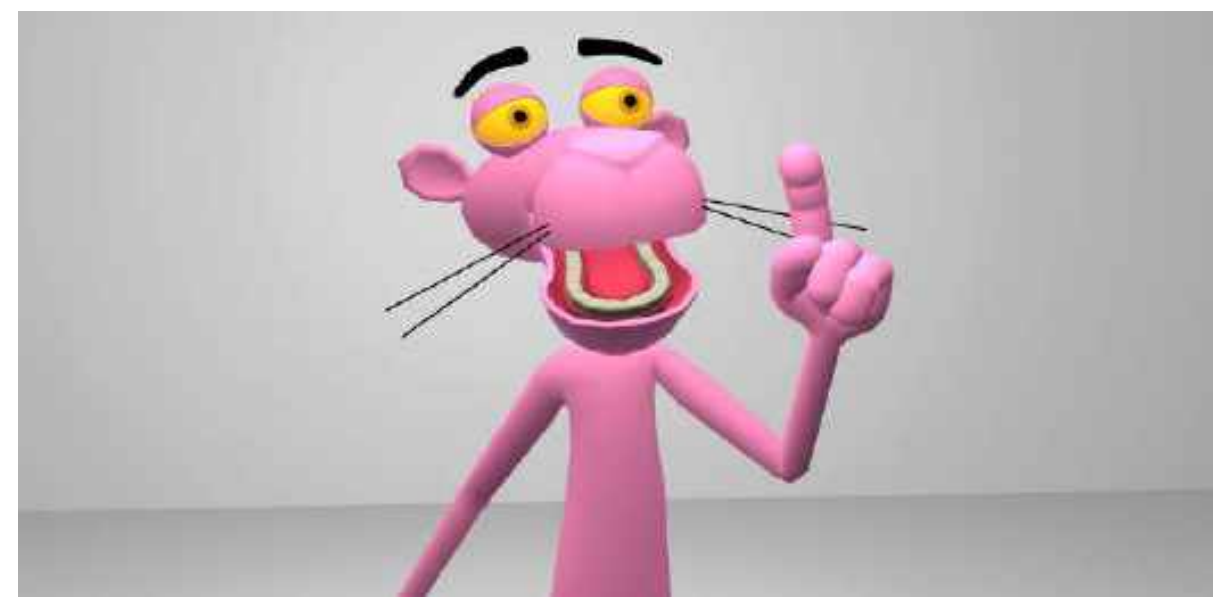

Imagen 9. Pantera Rosa. Fuente: registro de pantalla de los autores. Rig por: Karim Kashefi. Tomado de http://www.cgmeetup.net/forums/files/file/67-pink-panther/ (licencia de uso no comercial).

Una vez definido el personaje que se quería animar, empieza la exploración narrativa interpretativa que permite la experimentación con video referencias. Para tener una mejor dirección en la filmación de la escena, en esta etapa se contó con el acompañamiento de profesionales del campo teatral y cinematográfico. Una vez realizado el proceso de rodaje se pasó a una etapa de análisis y reinterpretación de la forma capturada para animarla. La descomposición del movimiento en sus poses clave facilitó el entendimiento de las acciones y de la caracterización del personaje. Las cuatro etapas realizadas fueron:

\section{Video Referencia}

Como se ve en el marco teórico, la necesidad de producir un material audiovisual que funcione como video referencia pensada para el desarrollo de una escena animada responde a necesidades técnicas y creativas, pues permite la repetición y segmentación de las mecánicas, así como el entendimiento de las 
expresiones e intenciones del actor. La locación por lo general no es relevante, pues los entornos se relacionan tradicionalmente por montaje, sin embargo, se adecua un espacio de trabajo que permite al equipo de trabajo la versatilidad de probar distintos ángulos y al actor desplazarse a través del espacio para el desarrollo de su interpretación. En el caso de este proyecto, el cual no contó con un guion estrictamente establecido, permite la construcción narrativa e interpretación durante el momento del registro, siendo otra posibilidad de flujo de trabajo (ver imagen 10).
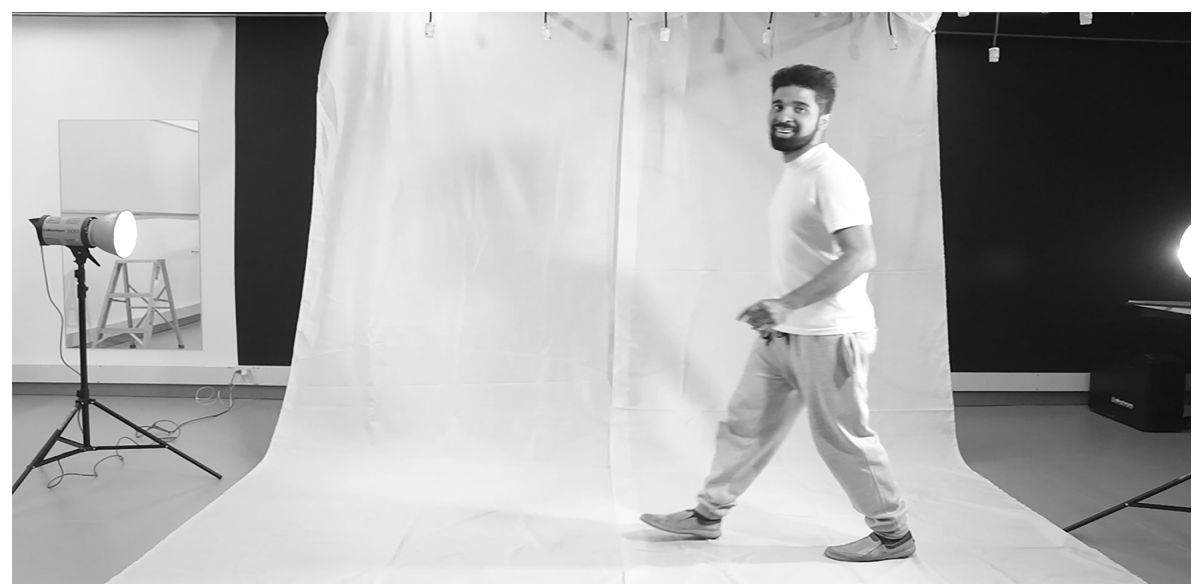

Imagen 10. Video referencia. Fuente: registro fotográfico los autores. Actor: Luis Escorcia.

\section{Abstracción de la forma}

Posterior al registro de la videoreferencia se seleccionó y depuró el material apropiado. Apoyado en software de video, se seleccionaron las secuencias mejor establecidas producto del registro directo o de un proceso de edición de diferentes fragmentos de las videoreferencias. Lo anterior se hizo para que 
se pudiera lograr una segmentación clara de las fases del movimiento y así comprender y visualizar de mejor manera el movimiento, similar al trabajo de Marey y Gilbreth. Una vez descompuesta la secuencia de video a fotogramas inicia el proceso de detección de momento y las poses claves, tomando como prioridad la estructura corporal como puntos de tensión, extensiones o compresiones del cuerpo, la plástica otorgada por el cuerpo del actor y su potencia a favor de la comunicación. Una vez seleccionados estos momentos, la estructura corporal se interpreta de manera más esquemática a manera de silueta para dejar en claro y con mayor comprensión la pose dentro de la acción que se quiere representar, estableciendo los fotogramas claves (ver imagen 11).

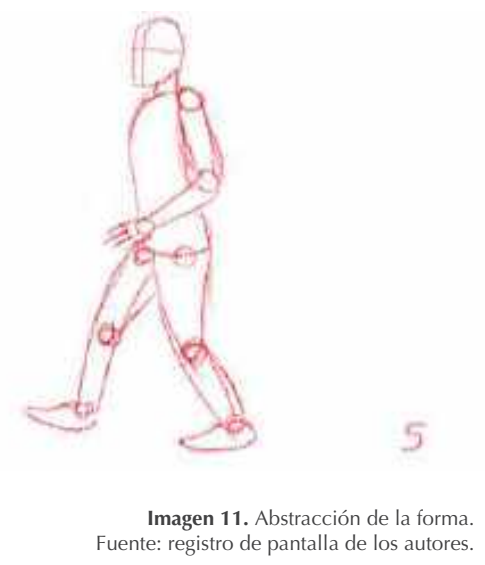

Es de anotar que no se hace uso del proceso de rotoscopiado pues, tal como lo señala Hooks, el animador debe hacer reacondicionamientos que el propio cuerpo no es capaz de hacer en pos de la figura animada. Adicionalmente, este proceso paralelo permite hacer que el animador tome conciencia de la lógica y forma del personaje, así como de la ideokinesis que debe tener en su construcción y que va interiorizando en la generación original de cada pose clave. 


\section{Análisis y adaptación de la forma}

En la abstracción de la imagen aún se considera la anatomía y estructura corporal del actor en referencia al proceso de Photostats que describen Thomas y Johnston (1981). Se intervienen las estructuras para adaptarlas a las formas animables. Como el rango de la plasticidad de un cuerpo animado es superior a la del cuerpo humano, se recurre al dibujo animado que otorga mayor versatilidad para adaptar la estructura del personaje animado. El análisis requerido en esta etapa implica la posible reacomodación de algunas partes del cuerpo para enfatizar en un punto estructural o generar una mayor lectura en la silueta del personaje. La construcción de la pose permite acentuar la distribución de los pesos corporales, establecer las líneas de acción y centros de equilibrio. Además, contempla la adición de atributos o partes extras como colas u orejas, que implican otro tipo de ritmos de animación adicionales a la estructura corporal. Esta etapa, siendo la previa al entorno tridimensional, puede extenderse o comprimirse dependiendo en la complejidad de la estructura corporal del personaje a representar y sus acciones a ejecutar (ver imagen 12).

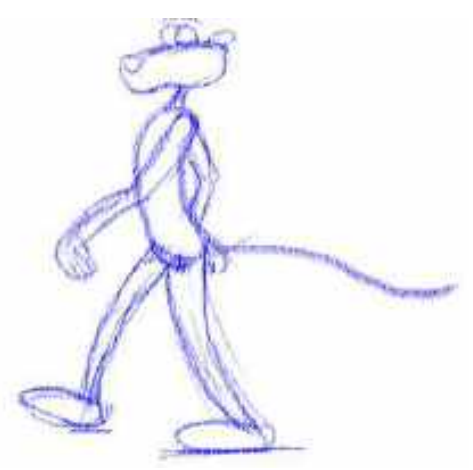




\section{Aplicación a personaje 3D animado}

Una vez comprendido el movimiento y las intenciones de las poses establecidas en las etapas anteriores, en el software tridimensional se construye cada una de las poses planeadas; a diferencia de una producción de dibujo animado o de stop-motion, la animación 3D permite las interpolaciones de una pose a otra de una manera automática. La tarea del animador de construir cada una de las poses clave y refinar las interpolaciones acentuando sus velocidad y direcciones, como etapa final en este proceso, requiere de la mayor dedicación de tiempo y trabajo para lograr los resultados esperados (ver imagen 13).

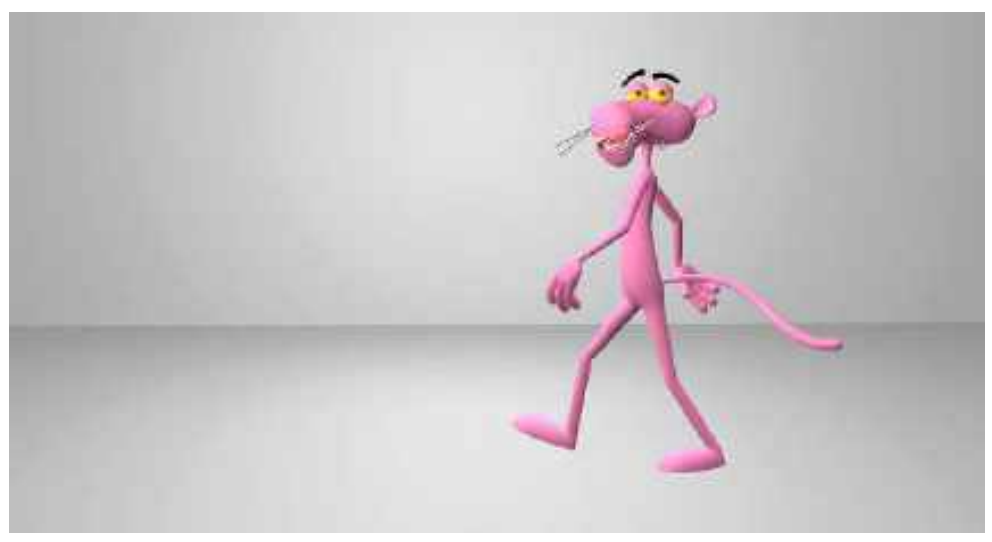

Imagen 13. Aplicación a personaje 3D animado. Fuente: registro de pantalla los autores. Rig por: Karim Kashefi. Tomado de http://www.cgmeetup.net/forums/files/file/67-pink-panther/ (licencia de uso no comercial).

En este punto se tienen que acomodar y revisar nuevamente las técnicas de las poses, los pesos, el equilibrio y la mecánica del personaje en pos de un movimiento que realmente tenga el appeal adecuado. Esto muestra la gran cantidad de variables y condiciones cambiantes que hay entre el proceso de Acting inicial, su segmentación, reinterpretación bidimensional y posterior traslado al ámbito 3D 
CGI, exigiendo al animador un entendimiento profundo de cada etapa para poder llegar a un resultado de calidad que pueda ser aceptado por el espectador.

El anterior proceso evidencia la necesidad de la apropiación de la videoreferencia, así como del análisis de la misma, para lograr la síntesis y abstracción de las formas y volúmenes de las acciones proyectadas a un personaje que va a ser animado. Identificando los momentos de tensión en la escena se procede entonces a la construcción de poses clave, las que se potencian usando los principios de animación presentados en la revisión teórica, afectando la continuidad y aspecto físico de la forma, buscando un mayor impacto comunicativo.

\section{Conclusiones}

El término Acting para animación puede entenderse como un proceso que proyecta atributos para la interpretación de personajes animados. Requiere así de un entendimiento profundo de la forma y el movimiento, que enfatiza en la separación en dos momentos principales:

1. Ejecución y registro del movimiento:

a. Manejo del cuerpo.

b. Dirección Actoral.

2. Análisis y representación del movimiento:

a. Pertinencia del material.

b. Depuración de la forma.

c. Optimización de la animación.

A lo largo de la ejecución práctica se pudo evidenciar que los protocolos para producir una escena animada pueden extenderse o comprimirse en consideración 
a los tiempos y al presupuesto de la producción. En el caso particular de la videoreferencia como herramienta de construcción, se puede deducir que fue efectiva y que el desarrollo interpretativo en esta etapa permitió una exploración focalizada para la construcción de la narrativa propia de cada práctica.

El uso de la improvisación como herramienta teatral fue clave para ofrecer en cortos periodos de tiempo diferentes interpretaciones de una misma escena con diferentes intenciones narrativas. Sin embargo, considerar la improvisación como el único elemento de desarrollo de la escena para animación durante el momento de registro de la videoreferencia, o como reemplazo de la planeación de la animación, no fue efectivo, porque la improvisación durante la generación de la escena proyectada a un proceso de animación puede traer un proceso confuso y no controlado que puede afectar el resultado final.

Para la captura de las videoreferencias se requiere que el animador, como el director de su propia escena animada, asuma el rol de dirección actoral ejercida sobre sí mismo o sobre alguien ajeno que realice las interpretaciones para la escena, porque debe considerar las intenciones teatrales y las acciones a registrar.

El proceso interpretativo y de personificación que tienen los actores y los animadores que asumen el rol de los actores para producciones animadas, presentan diferencias y semejanzas. Se debe considerar que ambas disciplinas tienen una formación profesional para aprender a usar el cuerpo como una herramienta de comunicación para sus representaciones de la realidad, por ende, al conocer las propiedades físicas de la naturaleza que alteran el cuerpo, estas se hacen presentes en sus interpretaciones. Por lo anterior ambos profesionales deben aprender a controlar y manejar dichos aspectos como el peso, el equilibrio y los centros de gravedad para aplicarlo a las estructuras corporales que manejan. Sin embargo, la construcción del movimiento es diferente para ambos, y se debe recordar que las formas de pensar y concebir el 
movimiento tienen consideraciones distintas. Mientras uno parte de estímulos internos para proyectarlo en el hacer, el movimiento animado nace de la observación y análisis para buscar representarlo de la mejor forma posible.

La posibilidad de un estudio mayor, si se quiere aplicar y enfatizar el pensamiento teatral en un entorno animado, se abre a partir de hallazgos como los protocolos teatrales que se enunciaron en la tesis de Sierra-Monsalve (2015), donde se pueden ampliar los rangos de expresión y comunicación que un animador puede desarrollar, planteando nuevas dinámicas interpretativas potenciando la representación del movimiento.

\section{Referencias}

Alvarez-Villanueva, C. D. (2007). La nueva era de los dibujos animados gracias a la animación digital. Metodologías de análisis del film. Actas del I Congreso Internacional sobre Análisis Fílmico. Madrid: Edipo. p. 57-66 http://repositori.uji.es/xmlui/handle/10234/38380

Arce, R. (2014). La animación colombiana durante el siglo XX: una historia en construcción. Cuadernos de cine colombiano $N^{\circ}$ 20. Animación en Colombia: Una historia en movimiento, 20, 21-34. https://idartesencasa. gov.co/artes-audiovisuales/libros/cuadernos-de-cine-colombiano-no-20animacion-en-colombia-una-historia-en

Buchan, S., Kearney, R., Weihe, R., Crow, H., Harris, M., Surman, D., ... Wehn, K. (2006). Animated «Worlds». Eastleigh: John Libbey Publishing.

Cambridge. (2017). Acting. En Cambridge Dictionary. https://dictionary. cambridge.org/es/diccionario/ingles-espanol/acting

Cameron, J. (Director). (2009). Avatar [Película]. 20th Century Fox.

Cohl, É. (Director). (1908). Fantasmagorie [Película]. Gaumont. 
Cohl, É. (Director). (1912). The Newlyweds [Película]. Émile Cohl.

Durán, M. (2014). Las potencias de la imagen animada. Cuadernos de cine colombiano $N^{\circ}$ 20. Animación en Colombia: Una historia en movimiento, 20, 35-45. https://idartesencasa.gov.co/artes-audiovisuales/libros/cuadernosde-cine-colombiano-no-20-animacion-en-colombia-una-historia-en

Giedion, S. (1970). Mechanization Takes Command - A Contribution to anonymous history (3a ed.). New York: Oxford University Press.

Goldberg, E. (2008). Character Animation Crash Course! Los Ángeles: Silman-James Press.

Halas, J. \& Manvell, R. (1980). La técnica de los dibujos animados. London \& New York: Ediciones Omega.

Hooks, E. (2003). Acting for animation. Portsmouth: Heinemann.

Laban, R. (1966). Choreutics. Alton: Dance Books.

Lasseter, J. (Director). (1995). Toy Story [Película]. Walt Disney Studios Motion Pictures.

Laybourne, K. (1998). The Animation Book. a complete guide to animated filmmaking--from flip-books to sound cartoons to 3-D animation. New York: Three Rivers Press.

Lecoq, J. (2003). El cuerpo poético. Barcelona: Alba Editorial.

Linares-Martínez, O. O. (2015). Criteria for Defining Animation: A Revision of the Definition of Animation in the Advent of Digital Moving Images. Animation: an interdiciplinary Journal, 10(1), 42-57. https://doi.org/ 10.1177/1746847715571234

Lorenzo-Hernández, M. C. (2020). Émile Cohl, animador de cartoons. http://hdl.handle.net/10251/136894 
McCay, W. (1911). Little Nemo in Slumberland. El Cajon: Sunday Press Books

McCay, W. (Director). (1914). Gertie the Dinosaur [Cortometraje]. Winsor McCay.

Muybridge, E. (2010). The human and animal locomotion photographs. Hong Kong: Taschen.

Naughty Dog (Programador). (2013). The Last of Us [Serie de videojuegos]. Sony Interactive Entertainment, SIE Worldwide Studios, Sony Interactive Entertainment Europe.

Patmore, C. (2004). Curso completo de animación. Barcelona: Editorial Acanto.

Pikkov, Ü. (2010). Animasophy. Theoretical writings on the animated film. Tallinn: Estonian Academy of Arts.

Real Academia Española. (2017). Actuación. En Diccionario de la Lengua Española. http://dle.rae.es/?w=diccionario

Sierra-Monsalve, S. H. (2015). Acciones Corporales Dinámicas. Metodología del movimiento físico para intérpretes escénicos inspirada en el Principio de Alteración del Equilibrio. Barcelona: Universitat Autònoma de Barcelona.

Telltale-Games. (Desarrollador). (2012). The Walking Dead [Videojuego]. Telltale Games.

Thomas, F. \& Johnston, O. (1981). Disney Animation: The Illusion of Life. New York: AbvevillePress.

Wikoff, B. W. (2009). Lines That Move: Winsor McCay's Work in Performance and Comics, 1900-1920. University of Cincinnati. http://rave.ohiolink.edu/ etdc/view?acc_num=ucin1243357215

Williams, R. (2001). The Animator's survival kit. London: Faber and Faber Limited.

Como citar: Guzmán-Ramírez, J. A. y Cabuya-Velandia, J. A. (2020). El acto de interpretación como proceso de identificación de atributos para la caracterización en personajes animados. Revista KEPES, 17(22), 301-343. https://doi.org/10.17151/kepes.2020.17.22.12 